\title{
Current weaknesses of breast conserving strategies after neoadjuvant chemotherapy in breast cancer treatment
}

\author{
Alejandro Martin Sanchez, Gianluca Franceschini, Lorenzo Scardina, Alba Di Leone, Riccardo Masetti \\ Multidisciplinary Breast Center, Fondazione Policlinico Universitario Agostino Gemelli, Università Cattolica del Sacro Cuore, Rome, Italy \\ Contributions: (I) Conception and design: AM Sanchez, R Masetti; (II) Administrative support: None; (III) Provision of study materials or patients: \\ None; (IV) Collection and assembly of data: L Scardina, A Di Leone; (V) Data analysis and interpretation: L Scardina, A Di Leone; (VI) Manuscript \\ writing: All authors; (VII) Final approval of manuscript: All authors. \\ Correspondence to: Alejandro Martin Sanchez, MD. Multidisciplinary Breast Center, Fondazione Policlinico Universitario Agostino Gemelli, \\ Università Cattolica del Sacro Cuore, Largo Agostino Gemelli 8, 00168 Rome, Italy. Email: martin.sanchez@hotmail.it.
}

\begin{abstract}
Locally advanced breast cancer (LABC) represents a worldwide major challenge, with a reported incidence reaching up to $90 \%$. In such setting, current guidelines advise for neoadjuvant chemotherapy (NACT) as primary approach to provide effective systemic treatment while surgically down-staging the cancer at presentation. Despite advantages of NACT, ranging a reported locoregional response rate from $30 \%$ to $70 \%$, several national surveys still describe higher mastectomy rates than expected. This phenomenon can be ascribed to radiology related factors, as the role of magnetic resonance imaging (MRI), despite having the highest correlation coefficient to final pathology, may still underestimate and overestimate tumor size, leading to surgical over and under treatment; surgeon related factors, as many breast surgeons routinely perform surgery based on pre-treatment characteristics rather than more appropriate posttreatment imaging and clinical results; patient related factors, as there is a well-documented tendency to prefer mastectomy instead of breast conservation therapy (BCT), in an attempt to reach better oncologic outcomes and hospital related factors, as there is too much variability between breast cancer centers, offering modern and minimally-invasive treatments and general hospitals, reporting a difficult access to advanced breast conserving strategies. In this context, the major part of this disinformation sequence in played by an important lacking of strong evidences, mostly regarding the oncologic outcomes of breast conserving surgery (BCS) and oncoplastic surgery (OS). Some recent high impact papers are reporting benefits of OS in LABC treatment, extending beyond improving cosmetic results, to the possibility of obtaining wider excisions with similar oncologic results as observed in patients submitted to classic BCS and mastectomy. Furthermore, what emerges from LABC literature is an imperative need of multidisciplinary breast centers worldwide diffusion, where breast-dedicated oncologists, radiologists and oncoplastic surgeons can offer patient-centered updated diagnostics, treatment protocols and surgical solutions, especially in a very delicate scenario, such as LABC treatment.
\end{abstract}

Keywords: Locally advanced breast cancer; neoadjuvant therapy; oncoplastic surgery; breast conserving surgery; mastectomy

Submitted Jul 06, 2017. Accepted for publication Aug 15, 2017.

doi: $10.21037 /$ tcr.2017.08.45

View this article at: http://dx.doi.org/10.21037/tcr.2017.08.45

\section{Introduction}

In screened countries, the use of mammography and increased public awareness of breast cancer have resulted in women having smaller tumors and fewer involved nodes at presentation, reducing cases of locally advanced primary diagnosis, intended as "large operable cases" at stage IIBIIIA (T3N0-1) and "truly inoperable cases" (Figure 1), with involvement of supraclavicular or internal mammary nodal 


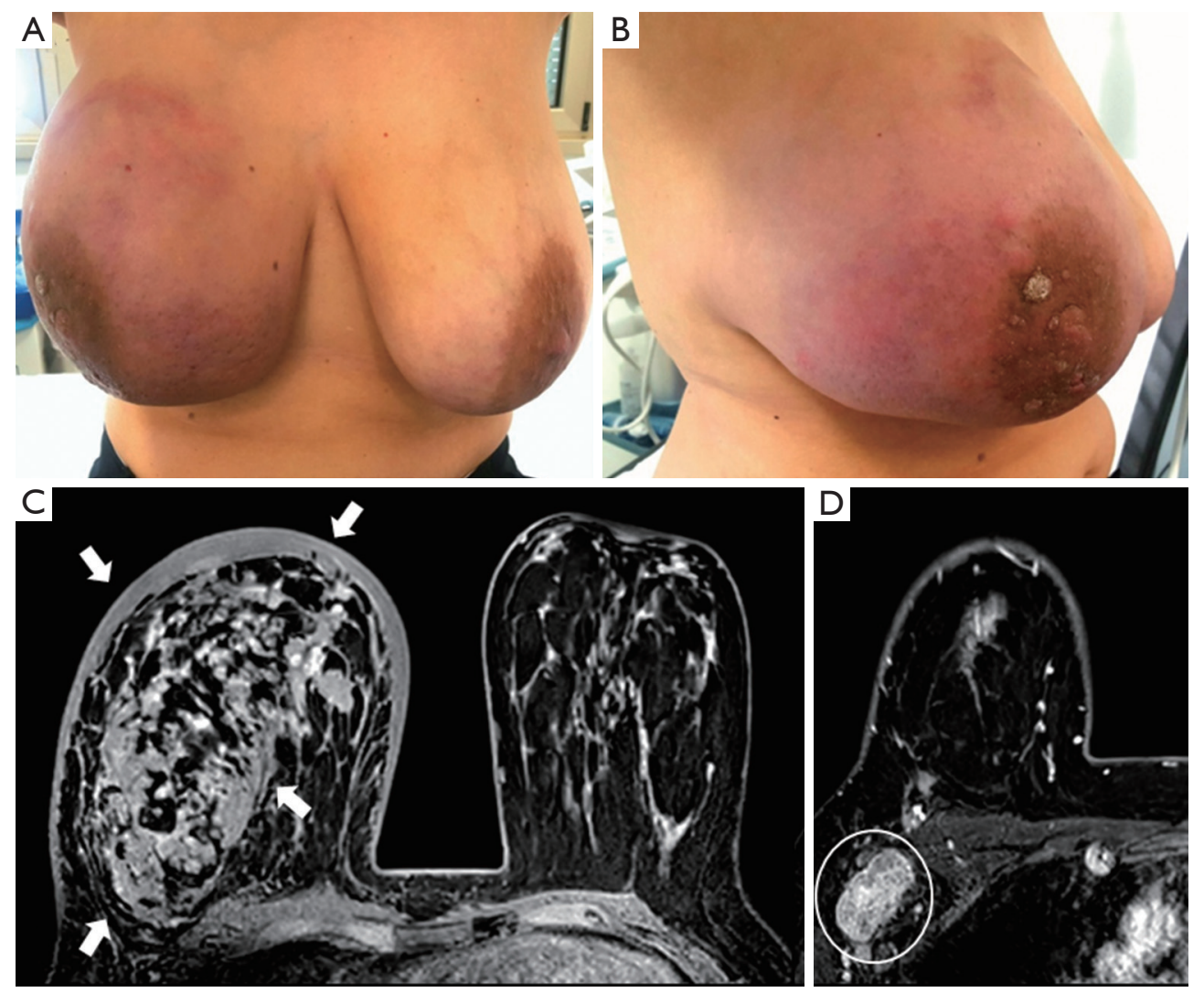

Figure 1 Patient with locally advanced ductal carcinoma of the right breast determining a diffuse ulcerative and inflammatory clinical presentation. (A) Front view with diffuse peau d'orange and nipple areola complex ulceration; (B) left view; (C) magnetic resonance imaging, showing right breast 15 -cm lesion, with skin involvement (arrows); (D) axillary lymph node involvement.

involvement (T4N2-3)/inflammatory breast cancer (IBC) (1).

Nevertheless, data emerging from National Cancer Database and the CONCORD high-resolution study reveal that approximately $8.5 \%$ of American and $4 \%$ of European patients still present with locally advanced breast cancer (LABC) (2); estimates that can reach up to $90 \%$ newly diagnosed breast cancers in low- to middle-income countries (3).

In such worldwide delicate setting, current guidelines advise for neoadjuvant chemotherapy (NACT) as primary treatment (4).

NACT achieves equivalent overall survival results, disease-free and distant disease recurrence that adjuvant systemic treatment (5-7) making the neoadjuvant approach a valid option, especially in breast cancer subtypes where the need for systemic therapy is clearly indicated, such as human epidermal growth factor receptor 2 (HER-2)positive and triple negative breast cancers (TNBC) $(8,9)$.
NACT rationale, is to offer effective systemic treatment while surgically down staging the cancer at presentation, potentially rendering operable patients who had been considered inoperable at the time of their diagnosis, as well as facilitating breast conserving surgery (BCS) when patients had initially needed mastectomy, with reported response rates ranging from $30 \%$ to $70 \%(10-15)$.

Besides the chance to pursue breast conservation, NACT also offers the potential advantage of gauging the sensitivity of the tumor to systemic therapy (16).

Moreover, pathological complete response to systemic therapy (no residual invasive disease in the breast and axilla regardless of the presence of residual in situ carcinoma) is a prognostic marker for long-term survival, especially in tumors with negative prognosis, such as TNBC disease (16,17-19).

Finally, in operable patients, NACT may offer the advantage over the adjuvant approach of anticipating 

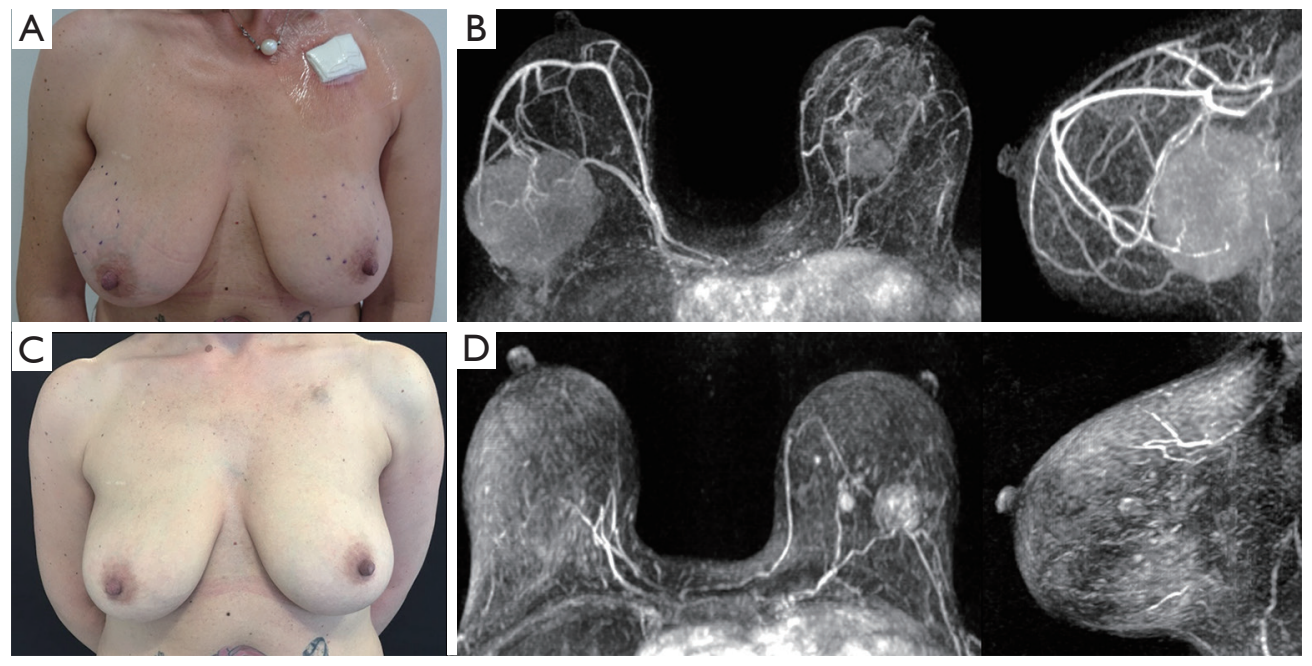

Figure 2 Clinical complete response to neoadjuvant chemotherapy. (A) Patient presenting with a massive T4 ductal carcinoma of the left breast with skin infiltration; (B) magnetic resonance reconstructions, confirming a 9-cm left breast malignant neoplasm, infiltrating pectoralis fascia and overlying skin; (C) clinical complete response; (D) magnetic resonance reconstructions, that confirmed a clinical complete response to neoadjuvant treatment.

administration of systemic treatment with a potential effect on systemic micrometastatic disease $(16,18)$.

Despite these brilliant results of NACT (Figure 2), that can potentially lead to a significant decrease in mastectomy rates, several national surveys reported lower BCS than expected.

In 2012, the European Society of Mastology (EUSOMA) reported the results from the EusomaDB survey (a prospective European database), which integrates data from European breast units located in Germany, Switzerland, Belgium, Austria, and Italy, reporting a mastectomy rate of $25.1 \%(20)$.

But a wide between-facilities variation was recently evidenced by a French survey, with mastectomy rates between $15.0 \%$ and $45.7 \%$ (21).

In 2012, a United Kingdom retrospective study on hospital episode statistics (NHS records) showed that among breast cancer patients, $42.3 \%$ underwent mastectomy as a primary procedure (22).

In the USA, the multicenter Surveillance Epidemiology and End Results (SEER) study, which covered approximately $28 \%$ of the U.S. population, confirmed in 2010 a decreasing trend in mastectomies (23) but subsequent reports revealed higher rates $(24,25)$ and in 2015 , a nationwide study on 2.7 million patients, conducted by the American Cancer Society and the American College of Surgeons Commission on Cancer finally revealed a mastectomy rate of $35.5 \%$ (26).
The lack of increased rates of BCS may be related to several difficulties:

\section{Radiology related factors}

After NACT, magnetic resonance imaging (MRI) has been proposed to have a role in guiding breast cancer surgery by measuring the size of residual tumor and has been shown to have highest sensitivity for detecting residual disease (27).

Currently, the role of MRI, despite having this highest correlation co-efficient to final pathology, may still underestimate and overestimate residual tumor size, leading to surgical over and under treatment.

A recent metanalysis confirmed that both over- and under-estimation by MRI are possible, and observed limit of agreement $( \pm 3.8 \mathrm{~cm})$ shows that errors within that range, that would be crucial for the choice of treatment are still possible and must be carefully avoided (28) by MRI skilled radiologists.

\section{Surgeon related factors}

Boughey et al. reported that in patients with T2 or T3 tumors, NACT lead to significantly less resected tissue than adjuvant chemotherapy, observing no change in rates of re-excision and thus leading to the conclusion that it is not necessary to excise the entire pre-chemotherapy volume of tissue (29). 
Nevertheless, many breast surgeons routinely perform surgery based on pre-treatment characteristics rather than more appropriate post-treatment imaging and clinical results. This commits patients to suboptimal cosmetic results or mastectomy.

\section{Patient related factors}

In his systematic review, Hamelinck et al. reported that $46 \%$ of breast cancer patients prefer mastectomy versus BCS, in an attempt to reach better oncologic outcomes (30).

This observation is a clear evidence that information between patient and clinicians is frequently lacking.

\section{Hospital related factors}

Lack of training in breast conserving procedures, such as oncoplastic surgery (OS) was identified in several studies worldwide, determining a high variability among specialized breast centers and general hospitals (31-33).

In Ontario, informal OS training opportunities exist; however, these are not well advertised or well known, leaving interested surgeons to seek out training in a piecemeal fashion (34).

In the United States, only $53 \%$ of recent breast surgical oncology fellowship graduates were comfortable performing oncoplastic breast surgery (35).

In their national French survey, Clough and colleagues reported a strong variability in implementation of Level 2 OS between surgeons (1.9-25.0\%), with higher and significantly different rate of level 2 OS in dedicated cancer centers versus public practices $(16.0 \%$ in dedicated cancer centers versus $7.6 \%$ in public hospitals) (21).

\section{Factors related to lacking evidences in surgical breast conservation}

Surgical management of breast cancer has undergone a continuous and dramatic evolution over the past 4 decades, trending away from radical procedures toward more breastconserving techniques, that provide patients with greater aesthetic satisfaction (36).

BCS followed by radiotherapy was confirmed by many randomized studies and meta-analyses as an alternative to mastectomy, reaching similar prognostic results while preserving the shape of the breast.

The traditional approach to BCS consists of incision placement over the tumor, resection to clinically and/or radiographically clear margins, and closure of skin without parenchymal closure, thus leaving a seroma cavity (37-40).

While this may provide adequate cosmesis in the immediate postoperative period, over time the seroma absorbs, leaving a breast contour deformity, which is exacerbated by adjuvant radiotherapy (41).

Factors known to contribute to poor cosmesis in BCS include high tumor volume to breast ratio, excision of $>20 \%$ of breast volume, tumor location, breast ptosis, and large body habitus $(42,43)$.

Given these conditions, poor cosmesis is verified in up to $40 \%$ of BCS patients and has been shown to significantly affect patients' quality of life and psychosocial outcomes (44-47).

In an attempt to optimize the balance between oncologic results and cosmetic outcomes, new surgical procedures that combine the principles of surgical oncology and plastic surgery have been introduced in recent years.

These new techniques called OS allow wider excisions with good oncologic outcomes, limiting the risk of a poor cosmesis (48-51) and further reducing mastectomy rates, thus improving patient's quality of life and self-esteem (Figure 3) (52,53) .

Initial studies on OS focused primarily on cosmetic results. Only a few large-scale studies have evaluated survival, recurrence rates, and other measures of oncologic safety (54-59).

As a consequence, OS was firstly established as a good compromise between larger excisions and good cosmetic results, but limited evidence hampered OS to become the oncologic leading solution for breast conserving treatment of breast cancer.

Something started to change 3 years ago, when in 2014, Losken and colleagues published a metanalysis that compared 24 OS papers $(3,165$ patients) versus 20 BCS papers (5,494 patients) reporting outcomes of both invasive and in situ breast cancer cases (60).

Their analysis evidenced a larger average tumor size in the OS group [ $2.7 \mathrm{~cm}$ in OS group versus $1.2 \mathrm{~cm}$ in breast conservation therapy (BCT) group] with a significant reduction in positive margin rate defined according to the American Society of Clinical Oncology (ASCO) and the American Society for Radiation Oncology (ASTRO) guidelines, as tumor cells at the cut edge of the surgical specimen (12\% in OS group versus $21 \%$ in BCS group) (61,62).

With an average follow-up of 37.1 months (range, $12.0-74.0$ months) in the OS group, versus 64.4 months (range, 30.0-240.0 months) in BCS group, the authors confirmed that OS lead to a significant reduction in local 

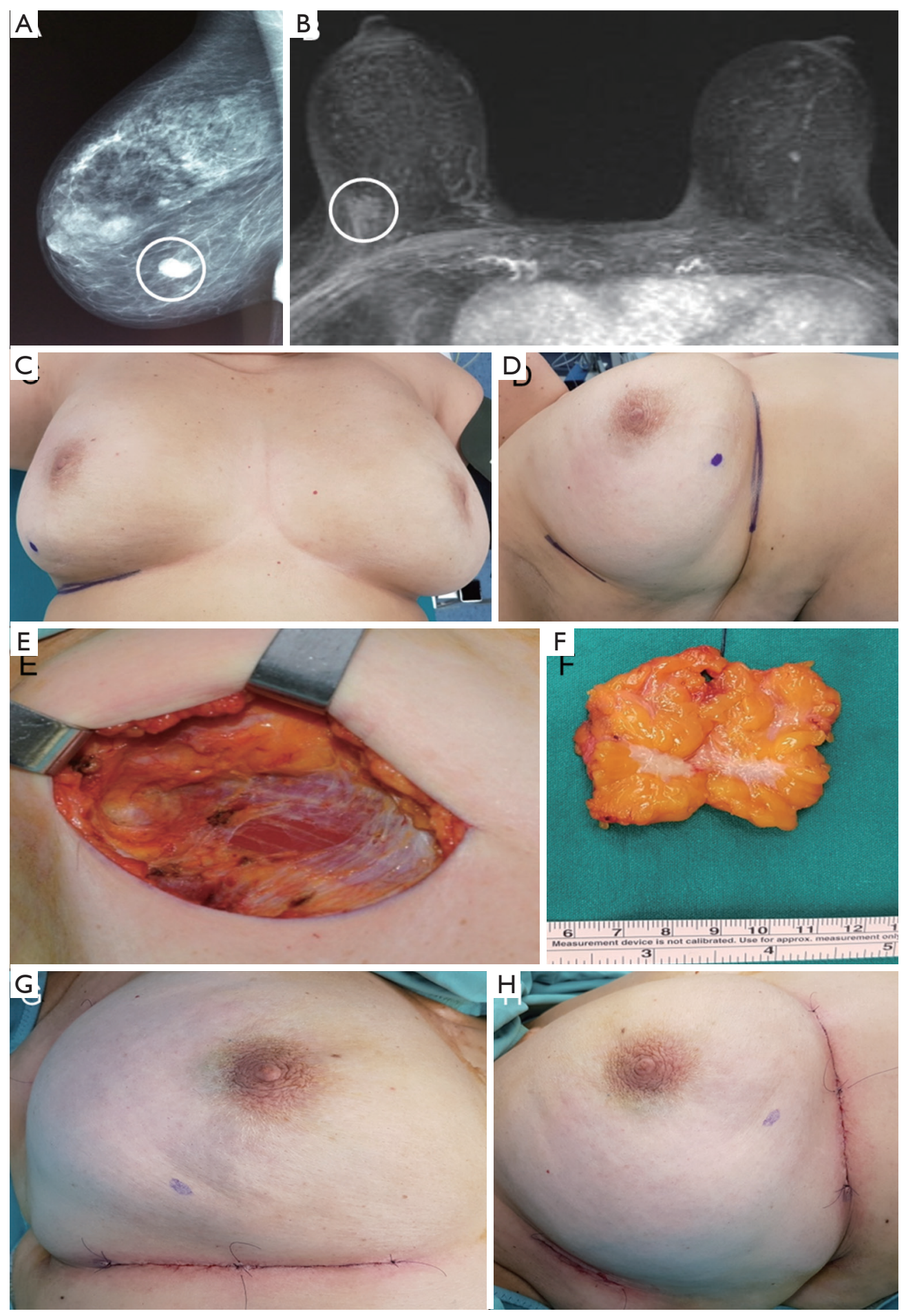

Figure 3 Oncoplastic inframammary fold approach of a lower outer right breast carcinoma. (A) Latero-lateral mammogram; (B) magnetic resonance reconstructions, confirming a 2.5-cm BIRADS4 right breast neoplasm; (C) preoperative assessment (front view); (D) preoperative assessment (lateral view); (E) outer external quadrantectomy with $20 \%$ of glandular tissue excision; (F) surgical specimen; (E) postoperative cosmetic result (front view); (F) postoperative cosmetic result (lateral view). 
recurrence rate $(4.2 \%$ after OS versus $7.0 \%$ after $\mathrm{BCS})$; with an overall cosmetic satisfaction of $90 \%$ in the OS group versus $80 \%$ in BCS group.

Recently, in their 2016 systematic review, De La Cruz and colleagues included 55 articles, collectively evaluating results on 6,011 patients treated for early-stage invasive breast cancer, with a mean tumor size of $23 \mathrm{~mm}(39.3 \%$ of T2 cases) and mean follow-up of 50.5 months (63).

Their analysis confirmed that OS enables surgeons to successfully remove greater volumes of mammary gland with wider surgical margins (thereby reducing positive margin, re-excision and secondary mastectomy rates), with excellent/good cosmetic outcomes $86 \%$ of cases.

The authors reported no statistically significant difference in the incidence of postoperative seromas, hematomas, infection, nipple necrosis and wound dehiscence among women undergoing OS and BCS and, concerning oncologic safety, no significant differences in overall survival, diseasefree survival and local recurrence rate.

In patients with locally advanced breast cancer who received NACT, the evidences scenario is even more complex, as literature reporting the use of BCS and OS is limited and confounding.

Actually, reported results of breast conservation evidenced a discordance between recurrence rates of less than $10 \%(64,65)$ and studies that reported recurrence rates above $20 \%(66,67)$.

Recent evidences seem to refute initial data. In their 2017 metanalysis, Zhou and colleagues reviewed 2000-2015 literature selecting eight trials, with a total of 3,215 patients analyzed: 1,361 receiving BCS and 1,854 who underwent mastectomy (68). At 5 years follow-up, the prevalence of local recurrence was $9.2 \%$ in the BCS group, versus $8.3 \%$ in the mastectomy group and overall survival was significantly higher in the BCS group, confirming response to NACT a major prognostic factor.

Regarding the use of oncoplastic techniques in this setting, Mazouni et al. published in 2013 a case-control study of patients undergoing NACT, including 214 patients receiving BCS and 45 patients receiving OS (69).

At presentation, $25.8 \%$ were $\mathrm{T} 3 / \mathrm{T} 4$ tumors and $44.8 \%$ had metastatic lymph node disease. Patients were initially treated with anthracycline, cyclophosphamide and 5 -fluorouracil (5-FU) with or without docetaxel. Regarding surgery, the average excised tumor size was similar for both groups $(40 \mathrm{~mm})$ but the authors confirmed greater specimen volumes excised in patients undergoing OS. At a median follow-up of 46 months, local recurrence rate was
$5 \%$ in BCS group versus $4 \%$ in OS group. No differences were observed regarding distant recurrence or survival.

Recently, Vieira et al. performed a matching case-control study, evaluating results of 78 patients with LABC who underwent NACT (doxorubicin-cyclophosphamide regimen followed by paclitaxel regimen). After completion of neoadjuvant treatment, 26 patients received OS, whereas $52 \mathrm{BCS}$. The authors reported an average size tumor of $5.25 \mathrm{~cm}(88.5 \%$ larger than $3 \mathrm{~cm}$ ). The clinical and pathological group characteristics were similar, except the weight of surgical specimens and surgical margins, which were higher in OS group. At 67.1 months of follow-up, local recurrence was $11.5 \%$ in BCS group, versus $7.7 \%$ in OS group. The authors reported no difference in locoregional recurrence, overall survival and disease specific survival (70).

\section{Conclusions}

Recent literature demonstrates the benefits of OS, extending far beyond the mere reduction in poor cosmetic results, to the possibility of obtaining wider excisions with similar oncologic results observed in patients submitted to classic BCS and mastectomy. Future studies with longer follow-up and standardization of data are needed. Furthermore, what emerges from LABC literature is an imperative need of multidisciplinary breast centers worldwide diffusion, where breast-dedicated oncologists, radiologists and OS trained surgeons can offer patient-centered updated diagnostics, treatment protocols and surgical solutions, especially in a very delicate scenario, such as $\mathrm{LABC}$ treatment.

\section{Acknowledgments}

Funding: None.

\section{Footnote}

Provenance and Peer Review: This article was commissioned by the editorial office, Translational Cancer Research for the series "Update of Current Evidences in Breast Cancer Multidisciplinary Management". The article has undergone external peer review.

Conflicts of Interest: All authors have completed the ICMJE uniform disclosure form (available at http://dx.doi. org/10.21037/tcr.2017.08.45). The series "Update of Current Evidences in Breast Cancer Multidisciplinary Management" was commissioned by the editorial office 
without any funding or sponsorship. GF served as the unpaid Guest Editor of the series and serves as an unpaid editorial board member of Translational Cancer Research from Nov 2016 to Dec 2018. AMF and RM served as the unpaid Guest Editors of the series. The authors have no other conflicts of interest to declare.

Ethical Statement: The authors are accountable for all aspects of the work in ensuring that questions related to the accuracy or integrity of any part of the work are appropriately investigated and resolved.

Open Access Statement: This is an Open Access article distributed in accordance with the Creative Commons Attribution-NonCommercial-NoDerivs 4.0 International License (CC BY-NC-ND 4.0), which permits the noncommercial replication and distribution of the article with the strict proviso that no changes or edits are made and the original work is properly cited (including links to both the formal publication through the relevant DOI and the license). See: https://creativecommons.org/licenses/by-nc-nd/4.0/.

\section{References}

1. Edge SB, Compton CC. The American Joint Committee on Cancer: the 7th edition of the AJCC cancer staging manual and the future of TNM. Ann Surg Oncol 2010;17:1471-4.

2. Allemani C, Sant M, Weir HK, et al. Breast cancer survival in the US and Europe: a CONCORD high-resolution study. Int J Cancer 2013;132:1170-81.

3. Brinton LA, Figueroa JD, Awuah B, et al. Breast cancer in Sub-Saharan Africa: opportunities for prevention. Breast Cancer Res Treat 2014;144:467-78.

4. CCN 2017 Guidelines. Available online: https://www. nccn.org/store/login/login.aspx?ReturnURL=https://www. nccn.org/professionals/physician_gls/pdf/breast.pdf

5. Bear HD, Anderson S, Smith RE, et al. Sequential preoperative or postoperative docetaxel added to preoperative doxorubicin plus cyclophosphamide for operable breast cancer: National Surgical Adjuvant Breast and Bowel Project Protocol B-27. J Clin Oncol 2006;24:2019-27.

6. Fisher B, Brown A, Mamounas E, et al. Effect of preoperative chemotherapy on local-regional disease in women with operable breast cancer: findings from National Surgical Adjuvant Breast and Bowel Project B-18. J Clin Oncol 1997;15:2483-93.

7. Mauri D, Pavlidis N, Ioannidis JP. Neoadjuvant versus adjuvant systemic treatment in breast cancer: a metaanalysis. J Natl Cancer Inst 2005;97:188-94.

8. Kaufmann M, von Minckwitz G, Mamounas EP, et al. Recommendations from an international consensus conference on the current status and future of neoadjuvant systemic therapy in primary breast cancer. Ann Surg Oncol 2012;19:1508-16.

9. Berruti A, Generali D, Kaufmann M, et al. International expert consensus on primary systemic therapy in the management of early breast cancer: highlights of the Fourth Symposium on Primary Systemic Therapy in the Management of Operable Breast Cancer, Cremona, Italy (2010). J Natl Cancer Inst Monogr 2011;2011:147-51.

10. Kaufmann M, Morrow M, von Minckwitz G, et al. Locoregional treatment of primary breast cancer: consensus recommendations from an International Expert Panel. Cancer 2010;116:1184-91.

11. Clough KB, Kaufman GJ, Nos C, et al. Improving breast cancer surgery: a classification and quadrant per quadrant atlas for oncoplastic surgery. Ann Surg Oncol 2010;17:1375-91.

12. von Minckwitz G. Neoadjuvant chemotherapy in breast cancer-insights from the German experience. Breast Cancer 2012;19:282-8.

13. Huober J, von Minckwitz G. Neoadjuvant Therapy What Have We Achieved in the Last 20 Years? Breast Care (Basel) 2011;6:419-26.

14. von Minckwitz G, Rezai M, Loibl S, et al. Capecitabine in addition to anthracycline- and taxane-based neoadjuvant treatment in patients with primary breast cancer: phase III GeparQuattro study. J Clin Oncol 2010;28:2015-23.

15. Barranger E, Antomarchi J, Chamorey E, et al. Effect of Neoadjuvant Chemotherapy on the Surgical Treatment of Patients With Locally Advanced Breast Cancer Requiring Initial Mastectomy. Clin Breast Cancer 2015;15:e231-5.

16. Liedtke C, Mazouni C, Hess KR, et al. Response to neoadjuvant therapy and long-term survival in patients with triple-negative breast cancer. J Clin Oncol 2008;26:1275-81.

17. Kong X, Moran MS, Zhang N, et al. Meta-analysis confirms achieving pathological complete response after neoadjuvant chemotherapy predicts favourable prognosis for breast cancer patients. Eur J Cancer 2011;47:2084-90.

18. von Minckwitz G, Untch M, Blohmer JU, et al. Definition and impact of pathologic complete response on prognosis after neoadjuvant chemotherapy in various intrinsic breast cancer subtypes. J Clin Oncol 2012;30:1796-804.

19. Cortazar P, Zhang L, Untch M, et al. Pathological complete response and long-term clinical benefit in breast cancer: the CTNeoBC pooled analysis. Lancet 
2014;384:164-72.

20. Garcia-Etienne CA, Tomatis M, Heil J, et al. Mastectomy trends for early-stage breast cancer: a report from the EUSOMA multi-institutional European database. Eur J Cancer 2012;48:1947-56.

21. Clough KB, Acosta-Marín V, Nos C, et al. Rates of Neoadjuvant Chemotherapy and Oncoplastic Surgery for Breast Cancer Surgery: A French National Survey. Ann Surg Oncol 2015;22:3504-11.

22. Jeevan R, Cromwell DA, Trivella M, et al. Reoperation rates after breast conserving surgery for breast cancer among women in England: retrospective study of hospital episode statistics. BMJ 2012;345:e4505.

23. Habermann EB, Abbott A, Parsons HM, et al. Are mastectomy rates really increasing in the United States? J Clin Oncol 2010;28:3437-41.

24. Mahmood U, Hanlon AL, Koshy M, et al. Increasing national mastectomy rates for the treatment of early stage breast cancer. Ann Surg Oncol 2013;20:1436-43.

25. McLaughlin SA. Surgical management of the breast: breast conservation therapy and mastectomy. Surg Clin North Am 2013;93:411-28.

26. Kummerow KL, Du L, Penson DF, et al. Nationwide trends in mastectomy for early-stage breast cancer. JAMA Surg 2015;150:9-16.

27. Marinovich ML, Houssami N, Macaskill P, et al. Metaanalysis of magnetic resonance imaging in detecting residual breast cancer after neoadjuvant therapy. J Natl Cancer Inst 2013;105:321-33.

28. Marinovich ML, Macaskill P, Irwig L, et al. Agreement between MRI and pathologic breast tumor size after neoadjuvant chemotherapy, and comparison with alternative tests: individual patient data meta-analysis. BMC Cancer 2015;15:662.

29. Boughey JC, Peintinger F, Meric-Bernstam F, et al. Impact of preoperative versus postoperative chemotherapy on the extent and number of surgical procedures in patients treated in randomized clinical trials for breast cancer. Ann Surg 2006;244:464-70.

30. Hamelinck VC, Bastiaannet E, Pieterse AH, et al. Patients' preferences for surgical and adjuvant systemic treatment in early breast cancer: a systematic review. Cancer Treat Rev 2014;40:1005-18.

31. Malycha PL, Gough IR, Margaritoni M, et al. Oncoplastic breast surgery: a global perspective on practice, availability, and training. World J Surg 2008;32:2570-7.

32. Zucca Matthes AG, Viera RA, Michelli RA, et al. The development of an Oncoplastic Training Center - OTC. Int J Surg 2012;10:265-9.
33. Yunaev M, Hingston G. Oncoplastic breast surgery in Australia and New Zealand-2014 and beyond. Gland Surg 2014;3:77-80.

34. Maxwell J, Roberts A, Cil T, et al. Current Practices and Barriers to the Integration of Oncoplastic Breast Surgery: A Canadian Perspective. Ann Surg Oncol 2016;23:3259-65.

35. Sclafani LM, Bleznak A, Kelly T, et al. Training a new generation of breast surgeons: are we succeeding? Ann Surg Oncol 2012;19:1856-61.

36. Franceschini G, Martin Sanchez A, Di Leone A, et al. New trends in breast cancer surgery: a therapeutic approach increasingly efficacy and respectful of the patient. G Chir 2015;36:145-52.

37. Jatoi I, Proschan MA. Randomized trials of breastconserving therapy versus mastectomy for primary breast cancer: a pooled analysis of updated results. Am J Clin Oncol 2005;28:289-94.

38. Poggi MM, Danforth DN, Sciuto LC, et al. Eighteenyear results in the treatment of early breast carcinoma with mastectomy versus breast conservation therapy: the National Cancer Institute Randomized Trial. Cancer 2003;98:697-702.

39. Simone NL, Dan T, Shih J, et al. Twenty-five year results of the national cancer institute randomized breast conservation trial. Breast Cancer Res Treat 2012;132:197-203.

40. Litière $S$, Werutsky G, Fentiman IS, et al. Breast conserving therapy versus mastectomy for stage I-II breast cancer: 20 year follow-up of the EORTC 10801 phase 3 randomised trial. Lancet Oncol 2012;13:412-9

41. Cochrane RA, Valasiadou P, Wilson AR, et al. Cosmesis and satisfaction after breast-conserving surgery correlates with the percentage of breast volume excised. Br J Surg 2003;90:1505-9.

42. Waljee JF, Hu ES, Newman LA, et al. Predictors of breast asymmetry after breast-conserving operation for breast cancer. J Am Coll Surg 2008;206:274-80.

43. Holmes DR, Schooler W, Smith R. Oncoplastic approaches to breast conservation. Int J Breast Cancer 2011;2011:303879.

44. Al-Ghazal SK, Fallowfield L, Blamey RW. Does cosmetic outcome from treatment of primary breast cancer influence psychosocial morbidity? Eur J Surg Oncol 1999;25:571-3.

45. Curran D, van Dongen JP, Aaronson NK, et al. Quality of life of early-stage breast cancer patients treated with radical mastectomy or breast-conserving procedures: results of EORTC Trial 10801. The European Organization for Research and Treatment of Cancer (EORTC), Breast Cancer Co-operative Group (BCCG). Eur J Cancer 1998;34:307-14.

46. Sneeuw KC, Aaronson NK, Yarnold JR, et al. Cosmetic and functional outcomes of breast conserving treatment for 
early stage breast cancer. 2 . Relationship with psychosocial functioning. Radiother Oncol 1992;25:160-6.

47. Waljee JF, Hu ES, Ubel PA, et al. Effect of esthetic outcome after breast-conserving surgery on psychosocial functioning and quality of life. J Clin Oncol 2008;26:3331-7.

48. Anderson BO, Masetti R, Silverstein MJ. Oncoplastic approaches to partial mastectomy: an overview of volumedisplacement techniques. Lancet Oncol 2005;6:145-57.

49. Nahabedian MY. editor. Oncoplastic Surgery of the Breast. Amsterdam: Saunders Elsevier, 2009.

50. Franceschini G, Sanchez AM, DI Leone A, et al. Integrated breast cancer surgical treatment: novel aspects of minimallyinvasive treatments. Minerva Chir 2016;71:146-55.

51. Franceschini G, Sanchez AM, Di Leone A, et al. Update on the surgical management of breast cancer. Ann Ital Chir 2015;86:89-99.

52. Veiga DF, Veiga-Filho J, Ribeiro LM, et al. Quality-oflife and self-esteem outcomes after oncoplastic breastconserving surgery. Plast Reconstr Surg 2010;125:811-7.

53. Santos G, Urban C, Edelweiss MI, et al. Long-Term Comparison of Aesthetical Outcomes After Oncoplastic Surgery and Lumpectomy in Breast Cancer Patients. Ann Surg Oncol 2015;22:2500-8.

54. Asgeirsson KS, Rasheed T, McCulley SJ, et al. Oncological and cosmetic outcomes of oncoplastic breast conserving surgery. Eur J Surg Oncol 2005;31:817-23.

55. Masetti R, Pirulli PG, Magno S, et al. Oncoplastic techniques in the conservative surgical treatment of breast cancer. Breast Cancer 2000;7:276-80.

56. Petit J, Rietjens M, Garusi C. Breast reconstructive techniques in cancer patients: which ones, when to apply, which immediate and long term risks? Crit Rev Oncol Hematol 2001;38:231-9.

57. Papp C, Wechselberger G, Schoeller T. Autologous breast reconstruction after breast-conserving cancer surgery. Plast Reconstr Surg 1998;102:1932-6; discussion 1937-8.

58. Losken A, Elwood ET, Styblo TM, et al. The role of reduction mammaplasty in reconstructing partial mastectomy defects. Plast Reconstr Surg 2002;109:968-75; discussion 976-7.

59. Spear SL, Pelletiere CV, Wolfe AJ, et al. Experience with reduction mammaplasty combined with breast conservation therapy in the treatment of breast cancer. Plast Reconstr Surg 2003;111:1102-9.

60. Losken A, Dugal CS, Styblo TM, et al. A meta-analysis comparing breast conservation therapy alone to the oncoplastic technique. Ann Plast Surg 2014;72:145-9.

61. Buchholz TA, Somerfield MR, Griggs JJ, et al. Margins for breast-conserving surgery with whole-breast irradiation in stage I and II invasive breast cancer: American Society of
Clinical Oncology endorsement of the Society of Surgical Oncology/American Society for Radiation Oncology consensus guideline. J Clin Oncol 2014;32:1502-6.

62. Moran MS, Schnitt SJ, Giuliano AE, et al. Society of Surgical Oncology-American Society for Radiation Oncology consensus guideline on margins for breast-conserving surgery with whole-breast irradiation in stages I and II invasive breast cancer. Ann Surg Oncol 2014;21:704-16.

63. De La Cruz L, Blankenship SA, Chatterjee A, et al. Outcomes After Oncoplastic Breast-Conserving Surgery in Breast Cancer Patients: A Systematic Literature Review. Ann Surg Oncol 2016;23:3247-58.

64. Cance WG, Carey LA, Calvo BF, et al. Long-term outcome of neoadjuvant therapy for locally advanced breast carcinoma: effective clinical downstaging allows breast preservation and predicts outstanding local control and survival. Ann Surg 2002;236:295-302; discussion 302-3.

65. Chen AM, Meric-Bernstam F, Hunt KK, et al. Breast conservation after neoadjuvant chemotherapy: the MD Anderson cancer center experience. J Clin Oncol 2004;22:2303-12.

66. Mauriac L, MacGrogan G, Avril A, et al. Neoadjuvant chemotherapy for operable breast carcinoma larger than

$3 \mathrm{~cm}$ : a unicentre randomized trial with a 124-month median follow-up. Institut Bergonié Bordeaux Groupe Sein (IBBGS). Ann Oncol 1999;10:47-52.

67. Rouzier R, Extra JM, Carton M, et al. Primary chemotherapy for operable breast cancer: incidence and prognostic significance of ipsilateral breast tumor recurrence after breast-conserving surgery. J Clin Oncol 2001;19:3828-35.

68. Zhou X, Li Y. Local Recurrence after Breast-Conserving Surgery and Mastectomy Following Neoadjuvant Chemotherapy for Locally Advanced Breast Cancer - a Meta-Analysis. Breast Care (Basel) 2016;11:345-51.

69. Mazouni C, Naveau A, Kane A, et al. The role of oncoplastic breast surgery in the management of breast cancer treated with primary chemotherapy. Breast 2013;22:1189-93.

70. Vieira RA, Carrara GF, Scapulatempo Neto C, et al. The role of oncoplastic breast conserving treatment for locally advanced breast tumors. A matching case-control study. Ann Med Surg (Lond) 2016;10:61-8.

Cite this article as: Sanchez AM, Franceschini G, Scardina L, Di Leone A, Masetti R. Current weaknesses of breast conserving strategies after neoadjuvant chemotherapy in breast cancer treatment. Transl Cancer Res 2018;7(Suppl 3):S356S364. doi: 10.21037/tcr.2017.08.45 